Article

\title{
Borneol Depresses P-Glycoprotein Function by a NF- $k$ B Signaling Mediated Mechanism in a Blood Brain Barrier in Vitro Model
}

\author{
Xiang Fan ${ }^{1,2, *}$, Lijuan Chai ${ }^{1,2}$, Han Zhang ${ }^{1,2}$, Yuefei Wang ${ }^{1,2}$, Boli Zhang ${ }^{1,2}$ and Xiumei Gao ${ }^{1,2}$ \\ Received: 1 September 2015 ; Accepted: 9 November 2015 ; Published: 18 November 2015 \\ Academic Editor: Gopinadhan Paliyath \\ 1 Institute of Traditional Chinese Medicine, Tianjin University of Traditional Chinese Medicine, \\ Tianjin 300193, China; cljuan1258@163.com (L.C.); zhanghan0023@126.com (H.Z.); \\ wangyuefei_2006@hotmail.com (Y.W.); zhangbolipr@163.com (B.Z.); gaoxiumei@tjutcm.edu.cn (X.G.) \\ 2 Tianjin State Key Laboratory of Modern Chinese Medicine, Tianjin University of Traditional Chinese \\ Medicine, Tianjin 300193, China \\ * Correspondence: fanxiang_78@hotmail.com; Tel.: +86-22-5959-6162; Fax: +86-22-2749-3265
}

\begin{abstract}
P-glycoprotein (P-gp) on brain microvascular endothelial cells (BMECs) that form the blood brain barrier (BBB), influences transportation of substances between blood and brain. The objective of this study was to characterize the effects of borneol on P-gp efflux function on BBB and explore the potential mechanisms. We established an in vitro BBB model comprised of rat BMECs and astrocytes to measure the effects of borneol on the known P-gp substrates transport across BBB, and examined the function and expression of P-gp in BMECs and the signaling pathways regulating P-gp expression. Borneol increased intracellular accumulation of Rhodamine 123 , enhanced verapamil and digoxin across the BBB in vitro model, and depressed mdr1a mRNA and P-gp expression. Borneol could activate nuclear factor- $\mathrm{kB}(\mathrm{NF}-\mathrm{kB})$ and inhibition of NF- $\mathrm{kB}$ with MG132 (carbobenzoxy-Leu-Leu-leucinal) and SN50 (an inhibitory peptide) obscuring the P-gp decreases induced by borneol. These data suggested that borneol depresses P-gp function in BMECs by a NF- $\mathrm{KB}$ signaling medicated mechanism in a BBB in vitro model.
\end{abstract}

Keywords: borneol; P-glycoprotein; brain microvascular endothelial cells; NF-kB; blood brain barrier

\section{Introduction}

The blood brain barrier (BBB) consisting of brain microvascular endothelial cells (BMECs) sealed together by continuous tight junctions plays a pivotal role to control the transportation of substances from blood to brain parenchyma and maintain brain microenvironment homeostasis [1]. P-glycoprotein (P-gp) and multidrug resistance-associated proteins have been shown to be expressed in BMECs, which can transport many physiological and pharmacological substances from the brain to the blood [2-4]. Transport medicated by these efflux pumps is important with respect to central nervous system drug clearance and limits drug delivery into the brain.

P-gp, a $170 \mathrm{kDa}$ glycoprotein, is one of the ATP-binding cassette (ABC) superfamily of membrane transporters and is encoded by multidrug resistance (MDR) genes [2,5]. Human MDR1 together with rodent mdrla and mdr1b selectively are identified with multidrug resistance. P-gp is an energy-dependent efflux pump and can transport a wide range of substances including morphine, phenytoin, flesinoxan, anti-cancer drugs, and anti-HIV drugs [6-9]. It has been reported that P-gp plays an important role in transporting lipid, endogenous opium peptide and naturally-occurring glucocorticoid cortisol, and regulating lipid metabolism [10,11]. 
Borneol (Figure 1), Chinese materia medica monomer (molecular weight 154.24), is extracted from Dryobalanops aromatica Gaertn $f$. and Blumea balsamifera DC, and is widely used for the treatment of cardiovascular and cerebrovascular diseases in China. Previous studies showed that borneol was able to improve the permeability of BBB by a physiological process, enhance penetration and accumulation of some drugs into the brain such as tetramethylpyrazine phosphate, gastrodin, puerarin, geniposide, kaempferol and nimodipine, and increase the brain bioavailability of these drugs [12-19]. The mechanisms of borneol opened BBB focused on loosening the endothelial tight junctions, increasing the number and volume of pinocytosis, and decreasing the mdr1a and mdr1b expression in hippocampus and hypothalamus [20-22]. Although previous studies showed the clear effects of borneol on improving other drugs or compounds transportation to the brain parenchyma, the mechanisms are still not well known.

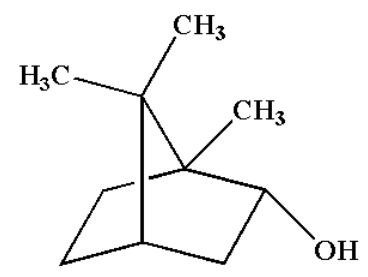

Figure 1. Chemical structure of borneol.

Because of the complexity of BBB control substances transport into the brain and the difficulty to explore the metabolisms in vivo, in vitro $\mathrm{BBB}$ models have been developed to study the screening substances according to their permeability across the BBB and related mechanisms. Compared with the in vivo, the principal advantages of the in vitro BBB models are the higher throughput capacity and the lower cost [23], in vitro BBB models also could unravel the complex cellular connections and molecular interactions that regulate the function and permeability of BBB [24]. In the present study, we established an in vitro BBB model comprised of rat BMECs and astrocytes to investigate the effects of borneol on the P-gp substrates transport through BBB as well as the intracellular mechanisms that regulate the effects of borneol on P-gp functions.

\section{Results}

\subsection{Cell Characterization and Establishment of an in Vitro BBB Model}

The primary rat BMECs presented a flat polygon-shaped phenotype and formed a monolayer characterized by being tightly packed and non-overlapping (Figure 2A). The BMECs were characterized by positive immunofluorescence staining with von Willebrand factor (vWF) antibody (Figure 2B). The primary astrocytes presented as star-shaped with numerous processes and formed layers of overlapping (Figure 2C), and were identified by positive glial fibrillary acidic protein (GFAP) immunofluorescence staining (Figure 2D). To test the functionality of the in vitro BBB model and the induction of tight junction complexes, the transendothelial electrical resistance (TEER) was measured. BMECs co-cultured with astrocytes showed a significant increase in TEER compared to mono-culture $(p<0.01)$ (Figure 2E). $\gamma$-Glutamyl transpeptidase $(\gamma$-GT) activity in isolated BMECs from co-culture and mono-culture was tested, $\gamma$-GT activity of BMECs in co-culture was seven-fold higher than that of mono-culture (Figure 2F). 
A

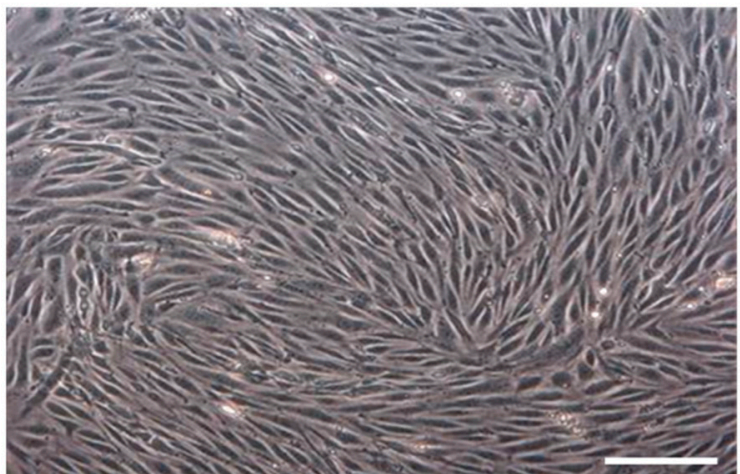

$\mathrm{C}$

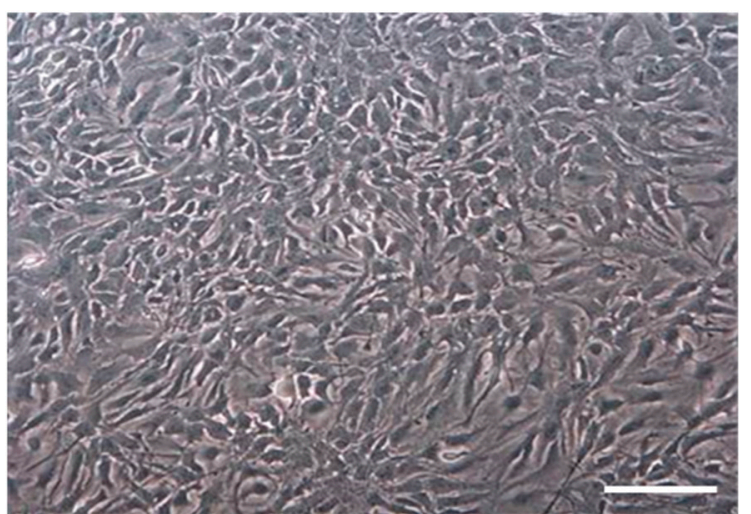

$\mathrm{E}$

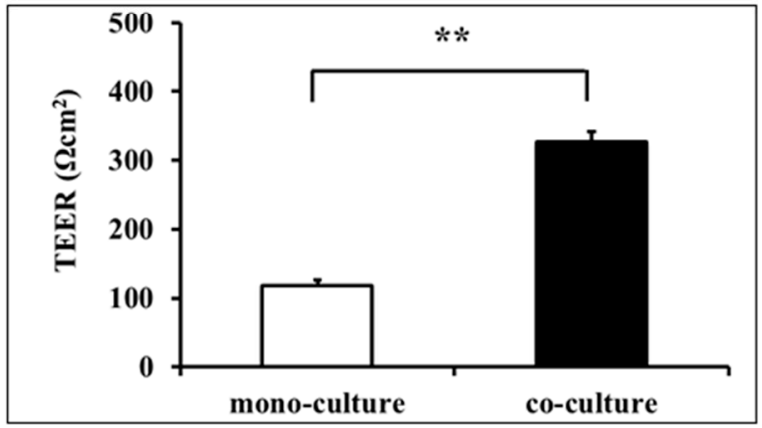

$\mathrm{B}$

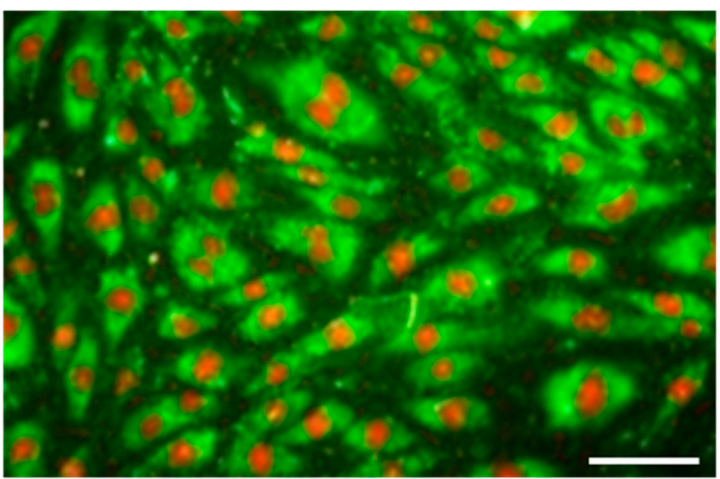

$\mathrm{D}$

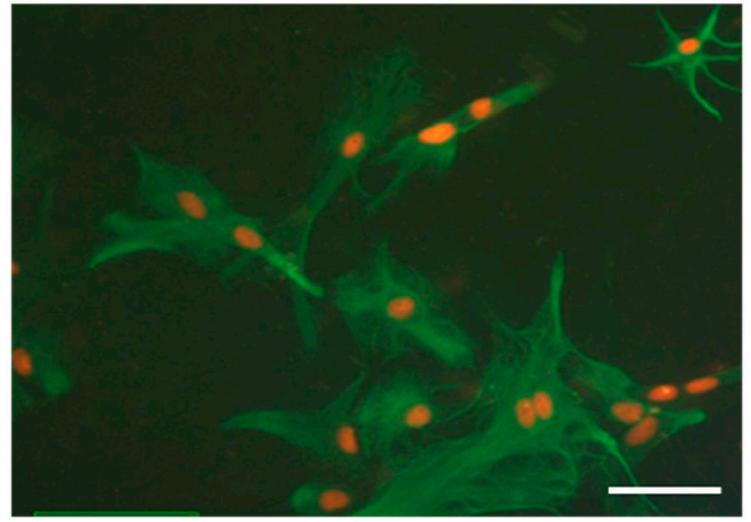

$\mathrm{F}$

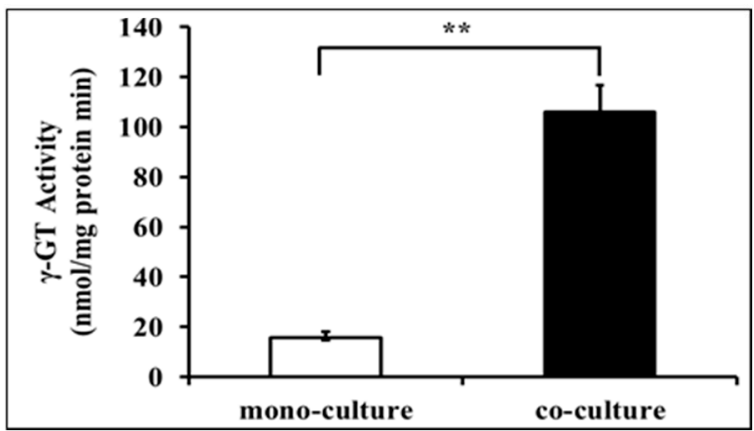

Figure 2. Cell characterization and establishment of the in vitro BBB model. (A) Representative image for primary rat BMECs, bar $=100 \mu \mathrm{m}$; (B) Representative vWF positive (green) and nucleus (red) immunofluorescence staining of BMECs, bar $=50 \mu \mathrm{m}$; (C) Representative image for primary rat astrocytes, bar $=100 \mu \mathrm{m}$; (D) Representative GFAP positive (green) and nucleus (red) immunofluorescence staining of astrocytes, bar $=50 \mu \mathrm{m}$; (E) TEER in mono-culture of BMECs and co-culture between BMECs and astrocytes; (F) $\gamma$-GT activity on BMECs. Data are expressed as mean $+\mathrm{SD} ;{ }^{* *} p<0.01(n=6$ per group).

\subsection{Borneol Down-Regulated P-gp Efflux Function}

Cyclosporin A (CsA), as P-gp inhibitor, strongly enhanced Rhodamine 123 (Rho123) uptake by BMECs, and similarly borneol treatment enhanced the BMECs uptake of the P-gp substrate Rho123 in a dose-dependent manner (Figure 3A). Amounts of $10 \mu \mathrm{g} / \mathrm{mL}$ and $20 \mu \mathrm{g} / \mathrm{mL}$ borneol significantly increased cellular accumulation of Rho123 in a time-dependent manner by approximately $40 \%$ and $50 \%$ increase respectively at $240 \mathrm{~min}$ after treatment (Figure 3B). Amounts of $10 \mu \mathrm{g} / \mathrm{mL}$ and $20 \mu \mathrm{g} / \mathrm{mL}$ borneol were able to increase digoxin across BBB in vitro at $4 \mathrm{~h}$ after treatment, especially $20 \mu \mathrm{g} / \mathrm{mL}$ 
borneol enhanced by approximately 50\% compared to control $(p<0.01)$ (Figure 3C). Similarly $10 \mu \mathrm{g} / \mathrm{mL}$ and $20 \mu \mathrm{g} / \mathrm{mL}$ borneol increased verapamil across BBB in vitro, especially $20 \mu \mathrm{g} / \mathrm{mL}$ borneol enhanced by approximately $37 \%$ compared to control $(p<0.01)$ (Figure 3D).

A

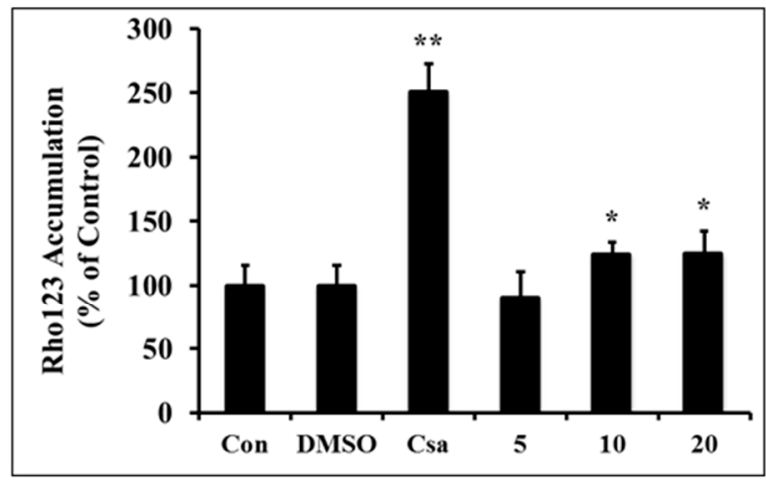

$\mathrm{C}$

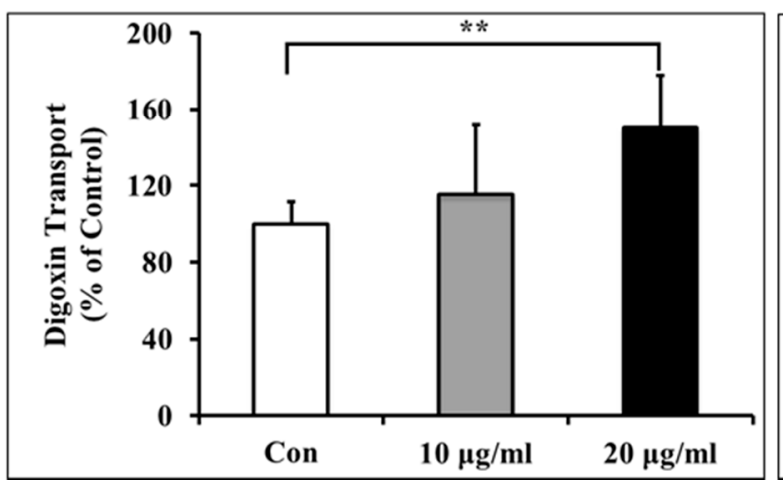

$\mathrm{B}$

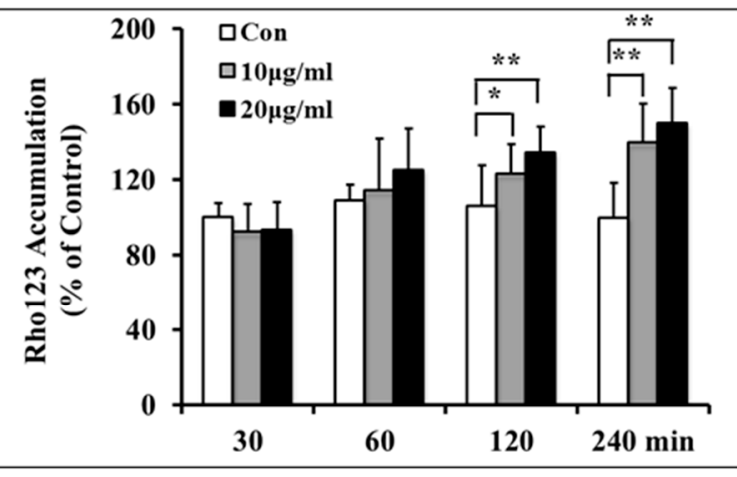

$\mathrm{D}$

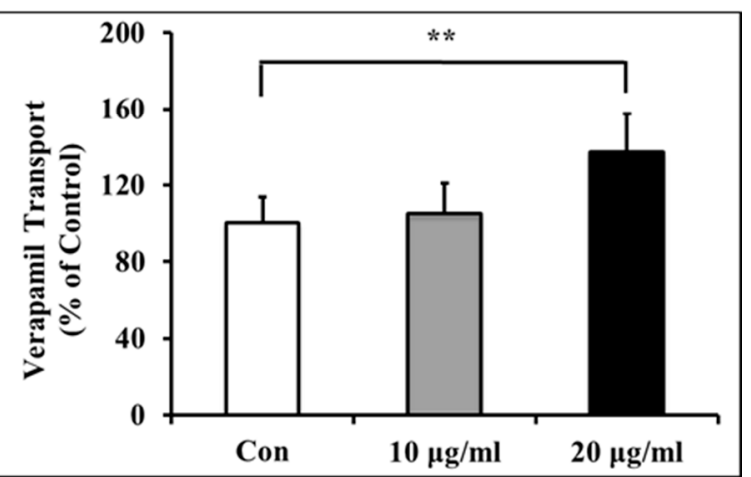

Figure 3. Effects of borneol on P-gp-mediated efflux function in BMECs. (A) Borneol increased the BMECs uptake of the P-gp substrate Rho123 in a dose-dependent manner. Con, control; DMSO, dimethyl sulphoxide; Csa, cyclosporin A; (B) Borneol increased cellular accumulation of Rho123 in a time-dependent manner; (C) Borneol enhanced P-gp substrate digoxin transport across the BBB in vitro model analyzed by high performance liquid chromatography (HPLC) at $4 \mathrm{~h}$ after treatment; (D) Borneol enhanced P-gp substrate verapamil transport across the BBB in vitro model analyzed by HPLC at $4 \mathrm{~h}$ after treatment. Data are expressed as mean $+\mathrm{SD} ;{ }^{*} p<0.05,{ }^{* *} p<0.01$ ( $n=8$ per group).

\subsection{Effects of Borneol on $m d r m R N A$ and P-gp Expression}

Borneol treatment decreased mdr1a mRNA expression in BMECs by a dose-dependent and time-dependent manner, and the mdr1a mRNA expression was minimum at $30 \mathrm{~min}$ to $1 \mathrm{~h}$ after treatment, then gradually went up at 2 to $4 \mathrm{~h}$ after treatment, but the levels were still lower than $0 \mathrm{~min}$ (Figure 4A). This indicated borneol could down-regulate mdr1a mRNA levels transiently and return to normal levels in a few hours. Borneol did not change mdr2 mRNA levels of BMECs (Figure 4B). Moreover, $10 \mu \mathrm{g} / \mathrm{mL}$ and $20 \mu \mathrm{g} / \mathrm{mL}$ borneol treatment decreased P-gp expression in BMECs, the reduction of P-gp expression were $27 \%$ and $58 \%$ compared to control group respectively at $4 \mathrm{~h}$ after treatment (Figure 4C,D). 
A

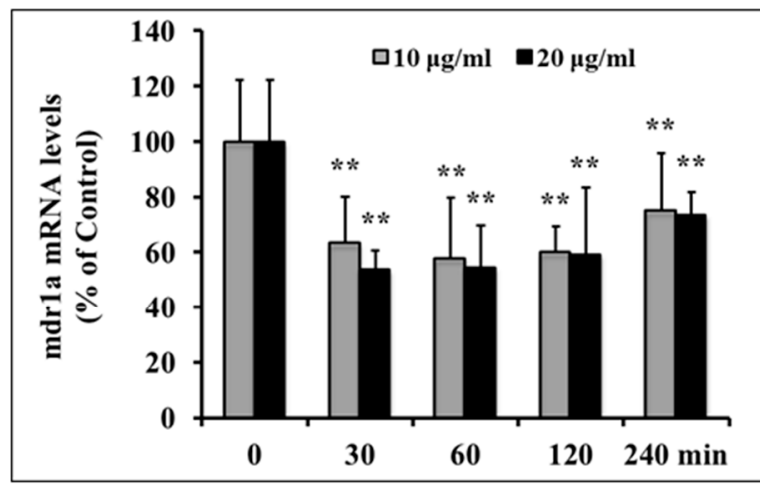

C

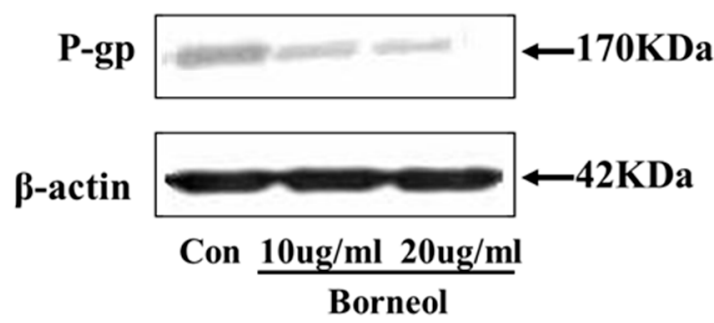

B

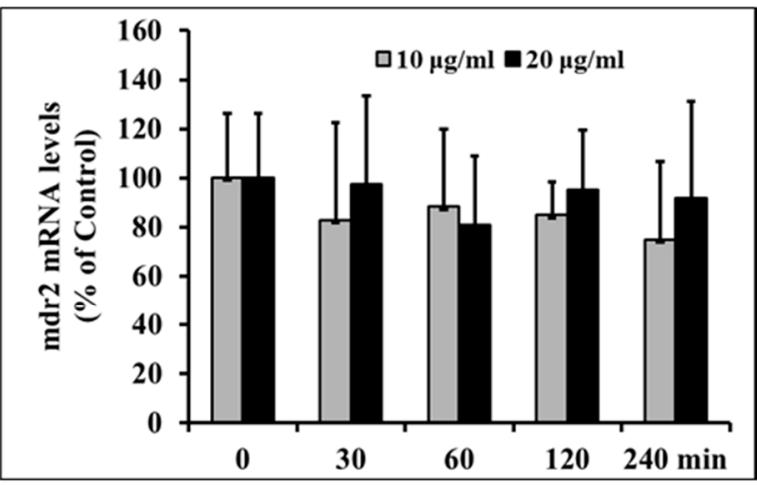

D

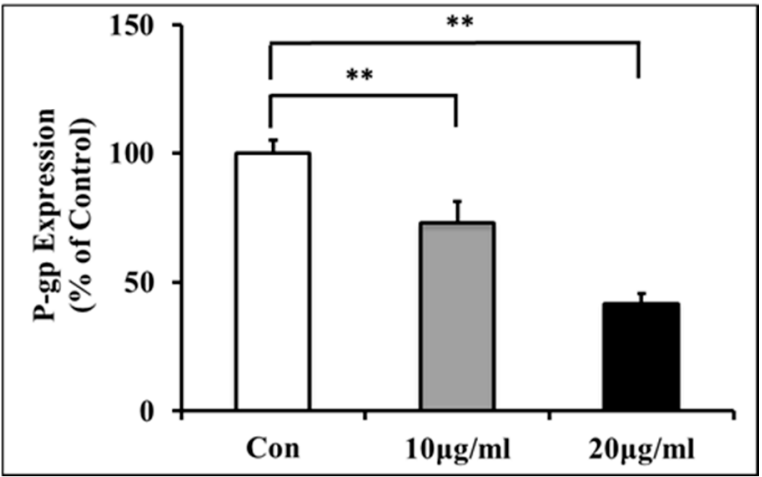

Figure 4. Effects of borneol on mdr mRNA and P-gp expression. (A) Borneol treatment decreased mdr1a mRNA expression in BMECs by a dose-dependent and time-dependent manner. Data are expressed as mean $+\mathrm{SD} ;{ }^{* *} p<0.01$, vs. 0 min. ( $n=8$ per group); (B) Borneol did not change mdr2 mRNA levels of BMECs; (C) Representative P-gp expression by western blot on BMECs treated with borneol; (D) Quantitative data of P-gp expression. Data are expressed as mean $+\mathrm{SD}$; ${ }^{* *} p<0.01(n=3$ per group).

\subsection{Depressed P-gp Expression in BMECs by Borneol via a NF-кB Mediated Mechanism}

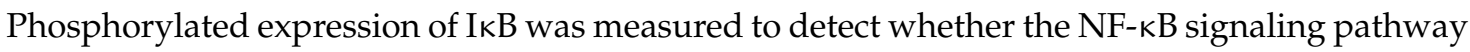
involved in the regulation of P-gp expression in BMECs treated with borneol. $10 \mu \mathrm{g} / \mathrm{mL}$ and $20 \mu \mathrm{g} / \mathrm{mL}$ borneol significantly increased phosphorylation of I $\mathrm{kB}$ expression at $30 \mathrm{~min}$ after treatment transiently. The elevated phosphorylation of IKB returned to control levels within 120 min after treatment (Figure 5A,B). BMECs were pre-incubated with the specific NF-kB inhibitors, MG132 $(10 \mu \mathrm{M})$ and SN50 $(20 \mu \mathrm{M})$, for $1 \mathrm{~h}$ and treated with $20 \mu \mathrm{g} / \mathrm{mL}$ borneol for $4 \mathrm{~h}$. Borneol treatment decreased P-gp expression in BMECs, while MG132 and SN50 obscured the borneol induced P-gp decreases (Figure 5C-F).

\section{Discussion}

Experimental results from this study showed borneol increased intracellular accumulation of Rho123, and enhanced P-gp substrates across the BBB in vitro, and also depressed mdr1a mRNA and P-gp expression. Furthermore, borneol could activate NF- $\kappa$ B and inhibition of NF- $\kappa$ B with MG132 and SN50 obscured the P-gp decreases induced by borneol. These data suggested that borneol depresses P-gp function in BMECs by a NF- $\mathrm{BB}$ signaling mediated mechanism in a BBB in vitro model. 


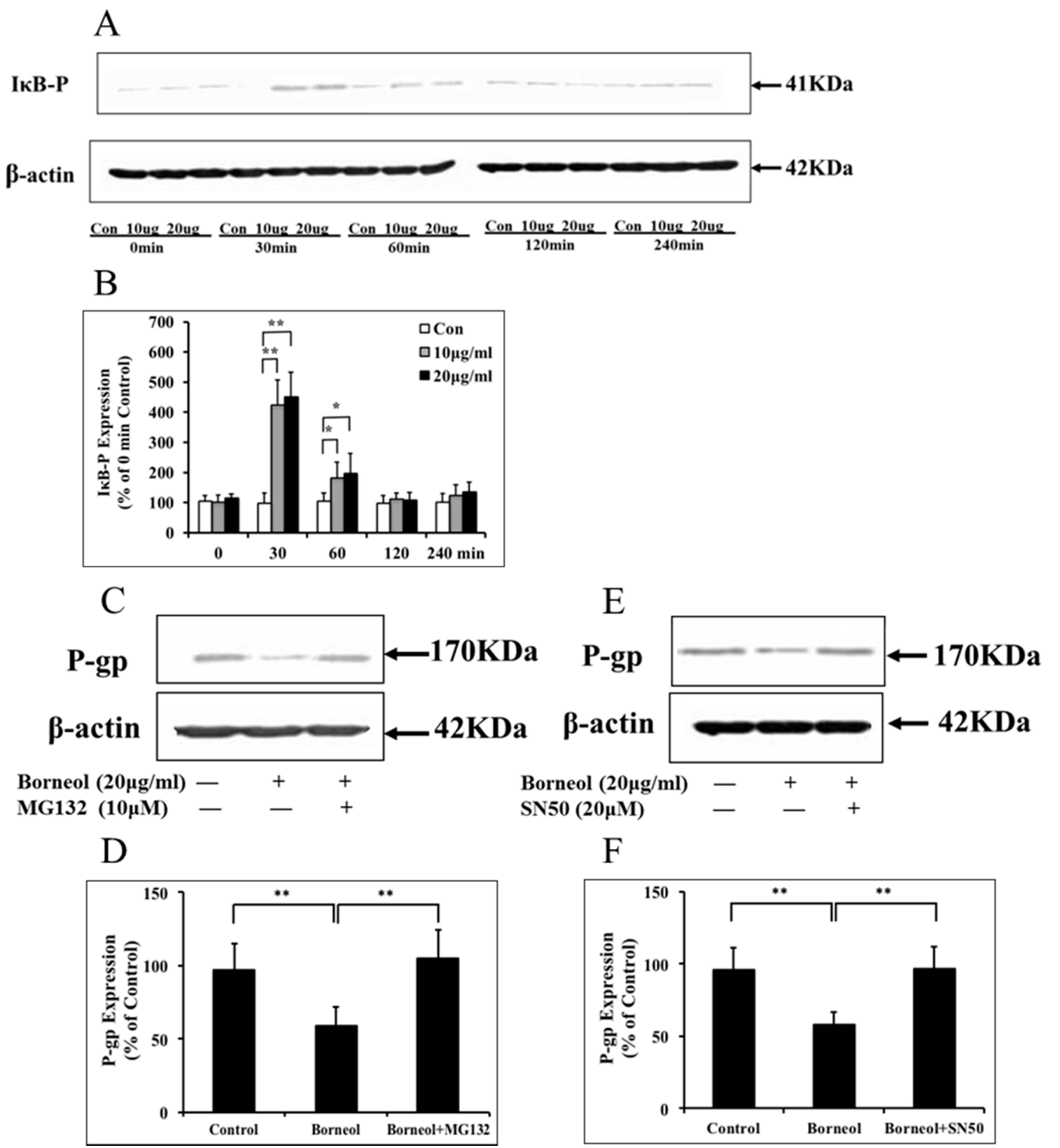

Figure 5. Measurement of NF- $\kappa \mathrm{B}$ expression in BMECs. (A) Representative phosphorylated IкB expression by Western blot on BMECs treated with borneol up to $4 \mathrm{~h}$; (B) Quantitative data of phosphorylated IкB expression; (C) Representative P-gp expression by Western blot on BMECs treated with borneol and borneol + MG132, respectively; (D) Quantitative data of P-gp expression; (E) Representative P-gp expression by Western blot on BMECs treated with borneol and borneol + SN50, respectively; (F) Quantitative data of P-gp expression. Data are expressed as mean $+\mathrm{SD} ;{ }^{*} p<0.05$, ** $p<0.01$ ( $n=3$ per group).

The BBB represents a complex cellular system which controls transportation of substances between blood and brain and maintains brain microenvironment homeostasis. In vivo studies are limited because of the complexity of the BBB structure as well as the difficulty to explore the metabolisms and transport of substances. For these reasons, in vitro BBB models have been developed. Previous studies suggested that astrocytes are able to induce BBB properties of endothelial cells, endothelial cell mono-culture or endothelial cells and astrocytes co-culture models have become the most widespread in vitro BBB models. In endothelial cell mono-culture, endothelial 
cells are seeded on the filter membrane of Transwell, and the astrocyte conditioned medium induced BBB properties of endothelial cells, whereas in non-contact co-culture, astrocytes are cultured on the bottom of the wells [25]. In both these models, the endothelial cells lose their BBB characteristics over time. In general, in vitro models should gather and keep as many BBB characteristics as possible. In this study, we established an in vitro BBB model comprising of rat BMECs and astrocytes, in which model astrocytes are cultured at the opposite sites of the polyethylene terephthalate (PET) membrane of Transwell with close contact with BMECs. The morphology of the primary BMECs in the present study was a typical feature of endothelial cells of BBB (Figure 2A), and the positive immunofluorescence staining with $\mathrm{vWF}$ antibody proved their endothelial origin and purity (Figure 2B). Previous studies demonstrated that cultured BMECs in vitro dedifferentiate very quickly and lose their specific characteristics of BBB $[26,27]$. Tight junctions between BMECs play an essential role to maintain the BBB function and properties [28]. The TEER correlated with the establishment of a tight junction has already been determined in MDCK cultures study [29]. The TEER in our established BBB in vitro model reached high levels, there was a very significant difference between BMECs co-culture with astrocytes and BMECs mono-culture (Figure 2E). Other studies also suggested astrocytes could increase $\gamma$-GT activity of vascular endothelial cells [30,31]. Our results agreed with these studies and showed significant increase of $\gamma$-GT activity in co-culture with closed contacts of the BMECs and astrocytes (Figure 2F). Compared with the endothelial cell mono-culture or endothelial cells and astrocytes no-contact co-culture models, the in vitro BBB model established in our study had special BBB characteristics of the higher TEER that indicated the paracellular permeability and BBB integrity, and higher expression of $\gamma$-GT, one of the key enzymes of the endothelial cells of BBB. In the present study, we successfully established the in vitro BBB model comprised of BMECs and astrocytes with the special BBB characterization.

Rho123 is a fluorescent dye which can be removed from the cells by P-gp, and P-gp function can be evaluated by Rho123 efflux assay in vitro and in vivo [32,33]. Therefore, an increased cellular accumulation of Rho123 is generally considered as the marker of diminished P-gp efflux function. However, it was interesting that borneol was able to decrease accumulation of Rho123 in BMECs by transporter mechanisms (Figure 3A,B). Also borneol could improve the known P-gp substrates, verapamil and digoxin, transport through the in vitro BBB model (Figure $3 C, D$ ). These data suggested that borneol could down-regulate P-gp efflux function and enhance P-gp substrates transport across BBB.

Previous studies demonstrated that brain concentrations of pharmacological agents were dramatically increased in mdr1a-deficient mice when compared to wild-type mice [34]. P-gp expressed on the luminal membrane of BMECs, which encoded by mdr1a, confers multidrug resistance to different chemotherapeutic agents [35]. Several extracellular stimulants have been reported to enhance MDR1 mRNA expression such as serum, mitogen stimulation, heavy metals, heat shock, and so on [36]. Our study demonstrates that borneol could down-regulate mdr1a mRNA levels at $30 \mathrm{~min}$ to $4 \mathrm{~h}$ after treatment (Figure $4 \mathrm{~A}$ ), and borneol cannot change the levels of mdr2 mRNA. Rodent mdr1a is predominant gene expressed in BMECs that selectively confers multidrug resistance. We confirmed the P-gp expression was suppressed by borneol at $4 \mathrm{~h}$ after treatment, probably because mdr1a mRNA expression was inhibited by borneol (Figure 4C,D). These data suggest that borneol could down-regulate P-gp efflux function by suppressing mdr1a mRNA and P-gp expression.

Recent studies have shown that factors released from brain parenchyma after ischemic stroke could potentially influence P-gp expression. $\mathrm{H}_{2} \mathrm{O}_{2}$ can increases P-gp expression in primary rat BMECs mediated by increased transcription and various signaling pathways, such as extracellular signal-regulated kinases (ERK) 1/2, protein kinase c (PKC), stress-activated protein kinases (SAPK) and protein kinase $\mathrm{B}$ (AKT) [37]. NF- $\mathrm{kB}$ is one of important pathways to modulate P-gp expression [38], previous studies also indicate that PI3-kinase can regulate human MDR1 expression via NF- $\mathrm{kB}$ [36], of which the binding site was located in the MDR1 promoter region upstream from the MDR1 transcription starting site [36,39]. It was reported that NF- $k B$ could regulate P-gp 
expression dependently in the liver and kidney [40,41]. The possible involvement of the NF- $\mathrm{KB}$ signaling pathway in P-gp expression in rat BMECs treated by borneol was tested. In the present study, we demonstrated that borneol depressed mdr1a mRNA and P-gp expression, and borneol activated NF- $\mathrm{kB}$ signaling transiently which peaked at $30 \mathrm{~min}$ and returned to control levels within 120 min after treatment (Figure 5A,B). Moreover, blockade of NF-kB by I $\kappa B$ degradation with MG132 or NF- $k B$ translocation with SN50 could obscure the borneol induced P-gp decreases (Figure 5C-F). It is possible that MG132 works more directly by blocking P-gp degradation and SN50 inhibits NF- $\mathrm{KB}$ translocation to the nucleus. In addition, there are reports that NF- $\mathrm{KB}$ has an inhibitory effect on P-gp expression in rat BMECs [38], and it can provide negative regulation of P-gp [42,43].

There are several caveats and limitations in this work. First, although the in vitro model was very similar to BBB in vivo and more convenient to study transport protein functions of BBB and related mechanisms, it is still a little different from the in vivo condition. Second, we only transiently treated the BBB in vitro with borneol for $4 \mathrm{~h}$, actually this is a short treatment time window. We did not monitor the long term effects of borneol on BBB function because of the culture limitation of in vitro BBB model. Further experiments to measure the multifactorial pathways of borneol on other substances especially Chinese materia medica across BBB in vivo would be clinically important.

\section{Experimental Section}

\subsection{Materials}

Dulbecco's minimum essential medium (DMEM), Type II collagenase, DNAse I were obtained from Invitrogen (Carlsbad, CA, USA). Collagenase/dispase and endothelial cell growth factor were purchased from Roche Molecular Biochemicals (Indianapolis, IN, USA). Fetal bovine serum (FBS) was obtained from Hyclon (Lgan, UT, USA). Bicinchoninic acid (BCA) protein assay reagent kit was obtained from Pierce (Rockford, IL, USA). Transwell inserts were purchased from Costar (Bethesda, MD, USA). Anti-P-gp monoclonal antibody was purchased from Calbiochem (La Jolla, CA, USA). The antibody to phospho-IкB, the horseradish peroxidase-conjugated secondary antibodies, and enhanced chemiluminescent (ECL) Western blotting detection reagents were purchased from Santa Cruz Biotechnology (Santa Cruz, CA, USA). The antibody to $\beta$-actin was from Sigma (St. Louis, MO, USA).

\subsection{Isolation and Culture of Rat Brain Microvascular Endothelial Cells}

A modified method described in the literature was used to isolate rat BMECs [44]. Briefly, 1-month-old Wistar rat cortices were dissected free of meninges and cut into small pieces on ice, then digested in a mixture of type II collagenase $(0.1 \%)$ and DNAse $(10 \mathrm{U} / \mathrm{mL})$ in DMEM for $1 \mathrm{~h}$ at $37^{\circ} \mathrm{C}$. The pellet was separated by centrifugation in 15\% dextran/PBS (4500 rpm, $20 \mathrm{~min}$ ) and further digested in $1 \mathrm{mg} / \mathrm{mL}$ collagenase/dispase and DNAse $(10 \mathrm{U} / \mathrm{mL})$ in DMEM for $1 \mathrm{~h}$ at $37^{\circ} \mathrm{C}$. After digestion, the pellet was re-suspended and layered over $50 \%$ continuous Percoll gradient. After centrifugation, microvascular fragments and cells were collected and seeded on gelatin coated tissue culture plates or culture flasks. BMECs-specific medium consisted of DMEM supplemented with 20\% FBS, $150 \mu \mathrm{g} / \mathrm{mL}$ endothelial cell growth factor, $100 \mu \mathrm{g} / \mathrm{mL}$ heparin, $2 \mathrm{mM} \mathrm{L}$-glutamine, $100 \mathrm{U} / \mathrm{mL}$ penicillin and $100 \mu \mathrm{g} / \mathrm{mL}$ streptomycin. BMECs were confirmed by immunofluorescence staining for vWF and fluorescein isothiocyanate (FITC)-conjugated secondary antibody.

\subsection{Isolation and Culture of Rat Astrocytes}

Astrocytes were isolated from the cerebral cortices of 1 to 2-day-old Wistar rat pups according to the previous methods [45]. The cerebral cortices were dissected free of meninges and cut into small pieces, then digested in $0.25 \%$ trypsin $/ 0.02 \%$ EDTA in PBS for 5 min at $37{ }^{\circ} \mathrm{C}$. The homogenized tissue was forced through a $100 \mu \mathrm{m}$ nylon sieve. After centrifugation, the pellets were re-suspended in DMEM (supplemented with 10\% FBS, $2 \mathrm{mM}$ L-glutamine, $100 \mathrm{U} / \mathrm{mL}$ penicillin and $100 \mu \mathrm{g} / \mathrm{mL}$ 
streptomycin) and plated into $75 \mathrm{~cm}^{2}$ tissue culture flasks. At 8 days of culture, the confluent astrocytes were shaken at $260 \mathrm{rpm}$ for $18 \mathrm{~h}$ at $37^{\circ} \mathrm{C}$ in order to eliminate the contaminating microglia and oligodendroglia. Astrocytes were confirmed by immunofluorescence staining for GFAP and FITC-conjugated secondary antibody.

\subsection{The Establishment of an in Vitro BBB Model}

The in vitro BBB model consisted of rat BMECs and astrocytes grown on two-sides of PET membrane of Transwell (Figure S1). Briefly, astrocytes $\left(1 \times 10^{5} / \mathrm{cm}^{2}\right.$ cells) were cultured on the opposite side of collagen-coated PET membrane of Transwell (Costar, pore size $0.4 \mathrm{~mm}$; diameter $12 \mathrm{~mm}$; insert growth area $1 \mathrm{~cm}^{2}$ ). When astrocytes grew about $60 \%$ confluent monolayer, BMECs $\left(2 \times 10^{5} / \mathrm{cm}^{2}\right.$ cells) were seeded on the upper side of the PET membrane in the apical chamber.

\subsection{Measurement of Transendothelial Electrical Resistance (TEER)}

The in vitro BBB model integrity was assessed by TEER measurement, according to previous methods [46]. The electrical resistance across the endothelial cells was measured by an ERS (Millicell, USA) (Figure S1). The electrical resistance of blank membranes of Transwell was subtracted from membranes with cells. TEER was shown as $\Omega \mathrm{cm}^{2}$.

\subsection{Measurement of $\gamma$-GT Activity in BMECs of the in Vitro BBB Model}

$\gamma$-GT activity of BMECs was measured as in previously described methods [47]. In brief, the BMECs were collected from the PET membrane of Transwell and sonicated for $15 \mathrm{~s}$ at $20 \mathrm{~W}$ with a Vibracell TM 75022 ultrasonic processor. $\gamma$-L-Glutamyl-p-nitroanilide and glycylglycine were used as substrates and the production of p-nitroaniline is considered as $\gamma$-GT activity. The absorbance of p-nitroaniline was measured at $540 \mathrm{~nm}$ and protein concentration was determined using the BCA assay.

\subsection{The Effects of Borneol on Rho123 Accumulation in BMECs}

Rho123 efflux assay was used to measure the activity of P-gp in BMECs according to previous methods [32]. BMECs grown to confluency in 24-well plates were treated with $5 \mu \mathrm{g} / \mathrm{mL}, 10 \mu \mathrm{g} / \mathrm{mL}$ and $20 \mu \mathrm{g} / \mathrm{mL}$ borneol, DMSO, CsA for $2 \mathrm{~h}$, or with $10 \mu \mathrm{g} / \mathrm{mL}$ and $20 \mu \mathrm{g} / \mathrm{mL}$ borneol for different times (30 min, $1 \mathrm{~h}, 2 \mathrm{~h}$, and $4 \mathrm{~h}$ ). Then BMECs were exposed to $5 \mu \mathrm{mol} / \mathrm{L}$ Rho123 in DMEM for $90 \mathrm{~min}$. After incubation with Rho123, BMECs were washed with ice-cold PBS and solubilized in 1\% $\mathrm{NaOH}$. Fluorescence of Rho123 was measured with emission wavelength at $535 \mathrm{~nm}$ and excitation wavelength at $485 \mathrm{~nm}$ using a fluorescence spectrophotometer (BioTek, Winooski, VT, USA). Rho123 levels were normalized to total cell protein and shown as nmol Rho123/mg protein.

\subsection{The Effects of Borneol on P-gp Substrates Transport through the in Vitro BBB Model}

To validate the effects of borneol on P-gp substrates transport through the in vitro BBB model, verapamil and digoxin, as known P-gp substrates, were measured. The medium from the apical compartments was replaced with $0.5 \mathrm{~mL}$ BMECs-specific medium including tested compounds (digoxin, digoxin $+10 \mu \mathrm{g} / \mathrm{mL}$ borneol, digoxin $+20 \mu \mathrm{g} / \mathrm{mL}$ borneol, verapamil, verapamil $+10 \mu \mathrm{g} / \mathrm{mL}$ borneol, verapamil $+20 \mu \mathrm{g} / \mathrm{mL}$ borneol) and the basal compartment with $1.5 \mathrm{~mL}$ BMECs-specific medium. At $4 \mathrm{~h}$ after treatment, medium was collected from the basal compartment for HPLC analysis. The ratio of the permeability concentration (apical to basal compartment) was then calculated.

\subsection{Real-Time RT-PCR Analysis}

Mdr gene expression in BMECs treated with borneol was determined by Real-time RT-PCR analysis as described earlier [48]. Briefly, total RNA was purified from BMECs treated by borneol with 
Trizol Reagent (Invitrogen, Carlsbad, CA, USA) according to the manufacture's instruction. cDNAs of the mdr1a, mdr2 and glyceraldehyde-3-phosphate dehydrogenase (GAPDH) were quantified using SYBR Green PCR Master Mix reagent kits (Applied Biosystems, Foster City, CA, USA) performed with the ABI PRISM 7300 Sequence Detection System. The following sequences of mdr1a, mdr2, and GAPDH were designed with Primer Express 2.0 (Applied Biosystems, Branchburg, NJ, USA) and used in present study: mdr1a forward, 5'-GCAGGTTGGCTGGACAGATT-3'; mdr1a reverse, 5'-GGAGCGCAATTCCATGGATA-3'; mdr1a probe, 5'-FAM-CCG CCA GAG TTC CCA GCA GCA TG-TAMRA-3'; mdr2 forward, 5'-AGTTCACGGGCGCATCAA-3'; mdr2 reverse, 5'-AAAAGACACTGGTGGCACGTT-3'; mdr2 probe, 5'-FAM-CAT CAA GTT CAT TGG TTT CCA CAT CCA GC-TAMRA-3'; GAPDH (an internal reference gene) forward, 5'-CCCCCAATGTATCCGTTGTG-3'; GAPDH reverse, 5'-TAGCCCAGGATGCCCTTTAGT-3'; GAPDH probe, 5'-FAM-TGC CGC CTG GAG AAA CCT GCC-TAMRA-3'. Comparative threshold cycle $\left(C_{t}\right)$ method was used to analyze data and $C_{t}$ values from mdr1a and mdr2 were normalized with the values from corresponding GAPDH reactions.

\subsection{Western Blot Analysis}

Western blot analysis was performed following the standard method [49]. Briefly, homogenates of BMECs treated with borneol were prepared in lysis buffer and protein concentrations were determined using the BCA protein assay, and equal amounts of protein were mixed with $2 \times$ SDS-PAGE sample loading buffer. After heating at $95{ }^{\circ} \mathrm{C}$ for $5 \mathrm{~min}$, proteins were loaded to $7.5 \%$ (for $\mathrm{P}$-gp) or $12 \%$ (for $\mathrm{I} \kappa \mathrm{B}$ ) tris-glycine gel and transferred to polyvinylidene difluoride membrane (Bio-Rad, Hercules, CA, USA) electrophoretically. Incubation was carried out with anti-P-gp (1:1000) antibody or anti-phosphospecific antibody to IKB (1:200) at $4{ }^{\circ} \mathrm{C}$ overnight and then with horseradish peroxidase-labeled secondary antibodies (1:2000) for $1 \mathrm{~h}$ at room temperature. Antibody positive bands representing the proteins of interest were visualized using ECL Western blot detection reagents. The band densities were measured by Quantity One software using Bio Imaging Systems (GeneGenius, SynGene, Cambridge, UK).

\subsection{Statistical Analysis}

Data were expressed as mean $+\mathrm{SD}$. All measurements were assessed with ANOVA, followed by Tukey-Kramer tests or Independent-Samples $t$ test. Differences with $p<0.05$ or $p<0.01$ were considered statistically significant.

\section{Conclusions}

Taken together, we have provided evidence that borneol can down-regulate P-gp efflux function, and decrease P-gp mRNA and protein expression in BMECs transiently by a NF- $\mathrm{kB}$ signaling mediated mechanism in a BBB in vitro model. This finding identifies the possibility that borneol could provide a narrow time window for those usually impermeable drug P-gp substrates (many chemotherapeutics and Chinese materia medica) to selectively transport across BBB and enter the brain. In addition, this may contribute in identifying pharmacological targets that transiently reduce P-gp-mediated drug efflux function with minimal side effects.

Supplementary Materials: Supplementary materials can be found at http://www.mdpi.com/1422-0067/16/ 11/26051/s1.

Acknowledgments: This work was supported by National Basic Research Program of China (973 Program, 2005CB523400).

Author Contributions: Xiang Fan, Boli Zhang and Xiumei Gao conceived and designed the study. Xiang Fan, Lijuan Chai, Han Zhang and Yuefei Wang conducted the experiments. Xiang Fan performed the statistical analysis and drafted the manuscript. All authors read and approved the manuscript.

Conflicts of Interest: The authors declare no conflict of interest. 


\section{References}

1. Abbott, N.J.; Romero, I.A. Transporting therapeutics across the blood-brain barrier. Mol. Med. Today 1996, 2, 106-113. [CrossRef]

2. Schinkel, A.H. P-Glycoprotein, a gatekeeper in the blood-brain barrier. Adv. Drug Deliv. Rev. 1999, 36, 179-194. [CrossRef]

3. Miller, D.S.; Nobmann, S.N.; Gutmann, H.; Toeroek, M.; Drewe, J.; Fricker, G. Xenobiotic transport across isolated brain microvessels studied by confocal microscopy. Mol. Pharm. 2000, 58, 1357-1367.

4. Litman, T.; Druley, T.E.; Stein, W.D.; Bates, S.E. From MDR to MXR: New understanding of multidrug resistance systems, their properties and clinical significance. Cell. Mol. Life Sci. 2001, 58, 931-959. [CrossRef] [PubMed]

5. Ng, W.F.; Sarangi, F.; Zastawny, R.L.; Veinot-Drebot, L.; Ling, V. Identification of members of the P-glycoprotein multigene family. Mol. Cell. Biol. 1989, 9, 1224-1232. [CrossRef] [PubMed]

6. Letrent, S.P.; Pollack, G.M.; Brouwer, K.R.; Brouwer, K.L. Effects of a potent and specific P-glycoprotein inhibitor on the blood-brain barrier distribution and antinociceptive effect of morphine in the rat. Drug Metab. Dispos. Biol. Fate Chem. 1999, 27, 827-834. [PubMed]

7. Potschka, H.; Loscher, W. In vivo evidence for P-glycoprotein-mediated transport of phenytoin at the blood-brain barrier of rats. Epilepsia 2001, 42, 1231-1240. [CrossRef] [PubMed]

8. Van der Sandt, I.C.; Smolders, R.; Nabulsi, L.; Zuideveld, K.P.; de Boer, A.G.; Breimer, D.D. Active efflux of the 5-HT(1A) receptor agonist flesinoxan via P-glycoprotein at the blood-brain barrier. Eur. J. Pharm. Sci. 2001, 14, 81-86. [CrossRef]

9. Glynn, S.L.; Yazdanian, M. In vitro blood-brain barrier permeability of nevirapine compared to other HIV antiretroviral agents. J. Pharm. Sci. 1998, 87, 306-310. [CrossRef] [PubMed]

10. Karssen, A.M.; Meijer, O.C.; van der Sandt, I.C.; Lucassen, P.J.; de Lange, E.C.; de Boer, A.G.; de Kloet, E.R. Multidrug resistance P-glycoprotein hampers the access of cortisol but not of corticosterone to mouse and human brain. Endocrinology 2001, 142, 2686-2694. [CrossRef] [PubMed]

11. Dagenais, C.; Graff, C.L.; Pollack, G.M. Variable modulation of opioid brain uptake by P-glycoprotein in mice. Biochem. Pharm. 2004, 67, 269-276. [CrossRef] [PubMed]

12. Xiao, Y.-Y.; Ping, Q.N.; Chen, Z.-P. The enhancing effect of synthetical borneol on the absorption of tetramethylpyrazine phosphate in mouse. Int. J. Pharm. 2007, 337, 74-79.

13. Cai, Z.; Hou, S.; Li, Y.; Zhao, B.; Yang, Z.; Xu, S.; Pu, J. Effect of borneol on the distribution of gastrodin to the brain in mice via oral administration. J. Drug Target. 2008, 16, 178-184. [CrossRef] [PubMed]

14. Gao, C.; Li, X.; Li, Y.; Wang, L.; Xue, M. Pharmacokinetic interaction between puerarin and edaravone, and effect of borneol on the brain distribution kinetics of puerarin in rats. J. Pharm. Pharm. 2010, 62, 360-367. [CrossRef] [PubMed]

15. Yu, B.; Ruan, M.; Cui, X.B.; Guo, J.M.; Xu, L.; Dong, X.P. Effects of borneol on the pharmacokinetics of geniposide in cortex, hippocampus, hypothalamus and striatum of conscious rat by simultaneous brain microdialysis coupled with UPLC-MS. J. Pharm. Biomed. Anal. 2013, 77, 128-132. [CrossRef] [PubMed]

16. Zhang, Q.; Wu, D.; Wu, J.; Ou, Y.; Mu, C.; Han, B.; Zhang, Q. Improved blood-brain barrier distribution: Effect of borneol on the brain pharmacokinetics of kaempferol in rats by in vivo microdialysis sampling. J. Ethnopharm. 2015, 162, 270-277. [CrossRef] [PubMed]

17. Wu, C.; Liao, Q.; Yao, M.; Xu, X.; Zhou, Y.; Hou, X.; Xie, Z. Effect of natural borneol on the pharmacokinetics and distribution of nimodipine in mice. Eur. J. Drug Metab. Pharm. 2014, 39, 17-24. [CrossRef] [PubMed]

18. Chen, Z.; Gong, X.; Lu, Y.; Du, S.; Yang, Z.; Bai, J.; Li, P.; Wu, H. Enhancing effect of borneol and muscone on geniposide transport across the human nasal epithelial cell monolayer. PLoS ONE 2014, 9, 101414. [CrossRef] [PubMed]

19. Chen, Z.Z.; Lu, Y.; Du, S.Y.; Shang, K.X.; Cai, C.B. Influence of borneol and muscone on geniposide transport through MDCK and MDCK-MDR1 cells as blood-brain barrier in vitro model. Int. J. Pharm. 2013, 456, 73-79. [CrossRef] [PubMed]

20. Chen, Y.M.; Wang, N.S. Effect of borneol on the intercellular tight junction and pinocytosis vesicles in vitro blood-brain barrier model. Zhongguo Zhong Xi Yi Jie He Za Zhi 2004, 24, 632-634. [PubMed] 
21. Yu, B.; Lu, G.H.; Sun, Y.; Lin, X.; Fang, T.H. Effect of electroacupuncture combined with intragastric administration of borneol on the permeability of blood-brain barrier in the mouse. Zhen Ci Yan Jiu 2011, 36, 335-340. [PubMed]

22. Yu, B.; Ruan, M.; Dong, X.; Yu, Y.; Cheng, H. The mechanism of the opening of the blood-brain barrier by borneol: A pharmacodynamics and pharmacokinetics combination study. J. Ethnopharm. 2013, 150, 1096-1108. [CrossRef] [PubMed]

23. Lundquist, S.; Renftel, M.; Brillault, J.; Fenart, L.; Cecchelli, R.; Dehouck, M.P. Prediction of drug transport through the blood-brain barrier in vivo: A comparison between two in vitro cell models. Pharm. Res. 2002, 19, 976-981. [CrossRef] [PubMed]

24. Lundquist, S.; Renftel, M. The use of in vitro cell culture models for mechanistic studies and as permeability screens for the blood-brain barrier in the pharmaceutical industry-background and current status in the drug discovery process. Vasc. Pharm. 2002, 38, 355-364. [CrossRef]

25. Cohen-Kashi Malina, K.; Cooper, I.; Teichberg, V.I. Closing the gap between the in vivo and in vitro blood-brain barrier tightness. Brain Res. 2009, 1284, 12-21. [CrossRef] [PubMed]

26. Kondo, T.; Imaizumi, S.; Kato, I.; Yoshimoto, T. Isolation and culture of brain endothelial cells and establishment of in vitro blood-brain barrier model. Cell Transplant. 1994, 3, 35-37.

27. Ichikawa, N.; Naora, K.; Hirano, H.; Hashimoto, M.; Masumura, S.; Iwamoto, K. Isolation and primary culture of rat cerebral microvascular endothelial cells for studying drug transport in vitro. J. Pharm. Toxicol. Methods 1996, 36, 45-52. [CrossRef]

28. Wolburg, H.; Neuhaus, J.; Kniesel, U.; Krauss, B.; Schmid, E.M.; Ocalan, M.; Farrell, C.; Risau, W. Modulation of tight junction structure in blood-brain barrier endothelial cells. Effects of tissue culture, second messengers and cocultured astrocytes. J. Cell Sci. 1994, 107, 1347-1357. [PubMed]

29. Griepp, E.B.; Dolan, W.J.; Robbins, E.S.; Sabatini, D.D. Participation of plasma membrane proteins in the formation of tight junctions by cultured epithelial cells. J. Cell Biol. 1983, 96, 693-702. [CrossRef] [PubMed]

30. Hurwitz, A.A.; Berman, J.W.; Rashbaum, W.K.; Lyman, W.D. Human fetal astrocytes induce the expression of blood-brain barrier specific proteins by autologous endothelial cells. Brain Res. 1993, 625, 238-243. [CrossRef]

31. Hayashi, Y.; Nomura, M.; Yamagishi, S.; Harada, S.; Yamashita, J.; Yamamoto, H. Induction of various blood-brain barrier properties in non-neural endothelial cells by close apposition to co-cultured astrocytes. Glia 1997, 19, 13-26. [CrossRef]

32. Fontaine, M.; Elmquist, W.F.; Miller, D.W. Use of rhodamine 123 to examine the functional activity of P-glycoprotein in primary cultured brain microvessel endothelial cell monolayers. Life Sci. 1996, 59, 1521-1531. [CrossRef]

33. Kageyama, M.; Namiki, H.; Fukushima, H.; Terasaka, S.; Togawa, T.; Tanaka, A.; Ito, Y.; Shibata, N.; Takada, K. Effect of chronic administration of ritonavir on function of cytochrome P450 3A and P-glycoprotein in rats. Biol. Pharm. Bull. 2005, 28, 130-137. [CrossRef] [PubMed]

34. Schinkel, A.H.; Smit, J.J.; van Tellingen, O.; Beijnen, J.H.; Wagenaar, E.; van Deemter, L.; Mol, C.A.; van der Valk, M.A.; Robanus-Maandag, E.C.; te Riele, H.P.; et al. Disruption of the mouse mdr1a P-glycoprotein gene leads to a deficiency in the blood-brain barrier and to increased sensitivity to drugs. Cell 1994, 77, 491-502. [CrossRef]

35. Fardel, O.; Lecureur, V.; Guillouzo, A. The P-glycoprotein multidrug transporter. Gen. Pharm. 1996, 27, 1283-1291. [CrossRef]

36. Kuo, M.T.; Liu, Z.; Wei, Y.; Lin-Lee, Y.C.; Tatebe, S.; Mills, G.B.; Unate, H. Induction of human MDR1 gene expression by 2-acetylaminofluorene is mediated by effectors of the phosphoinositide 3-kinase pathway that activate NF-kB signaling. Oncogene 2002, 21, 1945-1954. [CrossRef] [PubMed]

37. Felix, R.A.; Barrand, M.A. P-glycoprotein expression in rat brain endothelial cells: Evidence for regulation by transient oxidative stress. J. Neurochem. 2002, 80, 64-72. [CrossRef] [PubMed]

38. Nwaozuzu, O.M.; Sellers, L.A.; Barrand, M.A. Signalling pathways influencing basal and $\mathrm{H}_{2} \mathrm{O}_{2}$-induced P-glycoprotein expression in endothelial cells derived from the blood-brain barrier. J. Neurochem. 2003, 87, 1043-1051. [CrossRef] [PubMed]

39. Bentires-Alj, M.; Barbu, V.; Fillet, M.; Chariot, A.; Relic, B.; Jacobs, N.; Gielen, J.; Merville, M.P.; Bours, V. NF- $\mathrm{BB}$ transcription factor induces drug resistance through MDR1 expression in cancer cells. Oncogene 2003, 22, 90-97. [CrossRef] [PubMed] 
40. Thevenod, F.; Friedmann, J.M.; Katsen, A.D.; Hauser, I.A. Up-regulation of multidrug resistance P-glycoprotein via nuclear factor- $\mathrm{kB}$ activation protects kidney proximal tubule cells from cadmium- and reactive oxygen species-induced apoptosis. J. Biol. Chem. 2000, 275, 1887-1896. [CrossRef] [PubMed]

41. Ros, J.E.; Schuetz, J.D.; Geuken, M.; Streetz, K.; Moshage, H.; Kuipers, F.; Manns, M.P.; Jansen, P.L.; Trautwein, C.; Muller, M. Induction of Mdr1b expression by tumor necrosis factor- $\alpha$ in rat liver cells is independent of p53 but requires NF- $\mathrm{BB}$ signaling. Hepatology 2001, 33, 1425-1431. [CrossRef] [PubMed]

42. Ogretmen, B.; Safa, A.R. Negative regulation of MDR1 promoter activity in MCF-7, but not in multidrug resistant MCF-7/Adr, cells by cross-coupled NF- $\mathrm{kB} / \mathrm{p} 65$ and c-Fos transcription factors and their interaction with the CAAT region. Biochemistry 1999, 38, 2189-2199. [CrossRef] [PubMed]

43. Sukhai, M.; Piquette-Miller, M. Regulation of the multidrug resistance genes by stress signals. J. Pharm. Pharm. Sci. 2000, 3, 268-280. [PubMed]

44. Abbott, N.J.; Hughes, C.C.; Revest, P.A.; Greenwood, J. Development and characterisation of a rat brain capillary endothelial culture: Towards an in vitro blood-brain barrier. J. Cell Sci. 1992, 103, 23-37. [PubMed]

45. McCarthy, K.D.; de Vellis, J. Preparation of separate astroglial and oligodendroglial cell cultures from rat cerebral tissue. J. Cell Biol. 1980, 85, 890-902. [CrossRef] [PubMed]

46. Rutten, M.J.; Hoover, R.L.; Karnovsky, M.J. Electrical resistance and macromolecular permeability of brain endothelial monolayer cultures. Brain Res. 1987, 425, 301-310. [CrossRef]

47. Orlowski, M.; Meister, A. The $\gamma$-glutamyl cycle: A possible transport system for amino acids. Proc. Nat. Acad. Sci. USA 1970, 67, 1248-1255. [CrossRef] [PubMed]

48. Wang, H.; Guo, Y.; Zhao, X.; Li, H.; Fan, G.; Mao, H.; Miao, L.; Gao, X. An estrogen receptor dependent mechanism of Oroxylin A in the repression of inflammatory response. PLoS ONE 2013, 8, 69555. [CrossRef] [PubMed]

49. Wang, H.; Gao, X.; Zhang, B. Tanshinone: An inhibitor of proliferation of vascular smooth muscle cells. J. Ethnopharm. 2005, 99, 93-98. [CrossRef] [PubMed]

(C) 2015 by the authors; licensee MDPI, Basel, Switzerland. This article is an open access article distributed under the terms and conditions of the Creative Commons by Attribution (CC-BY) license (http:/ / creativecommons.org/licenses/by/4.0/). 